\title{
A Comparative Study between Intravenous Fentanyl and Intravenous Lidocaine on Attenuation of Hemodynamic Pressor Responses to Laryngoscopic Intubation: A Prospective Cohort Study, Ethiopia
}

\author{
Hirbo Samuel1, Abateneh Melekamayhu1, Misrak Woldeyohannes', Siryet Tesfaye ${ }^{1}$, \\ Tewoderos Shitemaw ${ }^{2 *}$ \\ ${ }^{1}$ Department of Anesthesia, College of Medicine and Health Sciences, Addis Ababa University, Addis Ababa, Ethiopia \\ ${ }^{2}$ Department of Anesthesia, Arba Minch Health Science College, Arba Minch, Ethiopia \\ Email: samuelhirbo1@gmail.com, romeabaty@gmail.com, dzewege@yahoo.com, Siryetesfaye@gmail.com, \\ *tewoderosshitemaw@gmail.com
}

How to cite this paper: Samuel, H., Melekamayhu, A., Woldeyohannes, M., Tesfaye, S. and Shitemaw, T. (2019) A Comparative Study between Intravenous Fentanyl and Intravenous Lidocaine on Attenuation of Hemodynamic Pressor Responses to Laryngoscopic Intubation: A Prospective Cohort Study, Ethiopia. Open Journal of Anesthesiology, 9, 167-178.

https://doi.org/10.4236/ojanes.2019.99016

Received: October 30, 2018

Accepted: September 6, 2019

Published: September 9, 2019

Copyright $\odot 2019$ by author(s) and Scientific Research Publishing Inc. This work is licensed under the Creative Commons Attribution International License (CC BY 4.0).

http://creativecommons.org/licenses/by/4.0/ (c) (i) Open Access

\begin{abstract}
Introduction: Laryngoscopic intubation is an insertion of endotracheal tube into the trachea for maintenance of airway during general anesthesia. Smooth intubation requires attenuation of pressor responses and maintenance of baseline hemodynamic stability. The primary outcome of this study is to compare intravenous fentanyl and lidocaine as an anesthetics adjuvant on attenuation of hemodynamic pressor responses to Laryngoscopic intubation in elective surgical adult patients. Methods: This prospective cohort study recruits 114 patients who underwent elective surgery under general anesthesia with laryngoscopy and endotracheal tube intubation. The study was conducted from January 1, 2018 to March 30, 2018. Systemic random sampling technique was used to select the study participants. Those patients that received intravenous fentanyl 2 micrograms per kilogram three minutes before intubation as an anesthetics adjuvant are considered as Fentanyl-group (group F). The Lidocaine-group (group L) was those patients who receive $2 \%$ intravenous lidocaine 1.5 milligrams per kilogram three minutes before intubation as anesthetics adjuvant. Hemodynamic parameters (heart rate and blood pressure) and other variables were documented starting from 3 minutes before intubation to 5 minutes after intubation. Results: The mean heart rate at first minute after intubation was significantly lower in fentanyl group (98.91 \pm 15.6 beats per minute $(\mathrm{bpm}))$ compared to lidocaine $(107 \pm 15.45 \mathrm{bpm}), \mathrm{t}$ $(112)=2.8, p=0.006$. Systolic blood pressure was also significantly lower in
\end{abstract}


fentanyl group (141.9 \pm 18.9 millimeters of mercury $(\mathrm{mmHg}))$ compared to lidocaine $(150 \pm 18.098 \mathrm{mmHg}), \mathrm{t}(112)=2.45, \mathrm{p}=0.016$ at first minute after intubation. At third minute after intubation, heart rate was significantly lower in fentanyl group compared to lidocaine, $t$ (112), $p=0.037$. No difference was in heart rate and blood pressure among the group at $5^{\text {th }}$ minute after intubation ( $p>0.05$ ). Conclusion and Recommendations: Fentanyl was better on attenuation of hemodynamic pressor responses to laryngoscopic intubation when compared to lidocaine. Therefore, using fentanyl pre-operatively to attenuate pressor responses especially during intubation is important.

\section{Keywords}

Fentanyl, Hemodynamic Parameters, Hemodynamic Pressor Responses, Laryngoscopic Intubation, Lidocaine

\section{Introduction}

Manipulation of the airway is one of the most stressing moments of general anesthesia. Laryngoscopy, tracheal intubation and other airway manipulations may cause significant cerebral and systemic hemodynamic responses, including tachycardia, hypertension, ventricular tachycardia, myocardial ischemia and increased intracranial pressure [1]. It has been suggested that distension of the supraglottic tissues is the major cause of the sympatho adrenal response to Laryngoscopy [2].

Many drugs and techniques have been used to prevent the hyperdynamic responses induced by Laryngoscopy and Endotracheal intubation [1] but no single technique has gained universal acceptance. It is clinically impractical to achieve sufficient anesthetic depth for preventing hyper dynamic responses to intubation solely with an intravenous (IV) or inhalational agent. Therefore, a wide variety of anesthetics drug combinations, adjuvants, or both have been used in attempting to potentiate anesthetics effects while minimizing hemodynamic depression with varying success rates. Among those dexmedetomidine, beta blocker, opioids and lidocaine are usually used as adjuvants [3] [4].

Fentanyl brings hemodynamic stability during perioperative period by its action on cardiovascular and autonomic regulatory areas. It decreases sympathetic tone and increases parasympathetic tone. Fentanyl inhibits pituitary adrenal response directly or indirectly via hypothalamus. Low doses of fentanyl were employed because a large dose was led to muscular rigidity, bradycardia, nausea and vomiting. Large doses may also cause postoperative respiratory depression; especially in surgery with short duration of less than 1 hour [5].

Lidocaine attenuates the hemodynamic response to tracheal intubation by its direct myocardial depressant effect, central stimulant effect, and peripheral vasodilatory effect and it also suppresses the cough reflex, an effect on synaptic transmission [6]. 
Hemodynamic pressor responses are a common problem in patients undergoing general anesthesia with laryngoscopic intubation (LI). The mean blood pressure and heart rate are increased by $30 \%$ and $22 \%$ respectively from baseline values during laryngoscopic intubation [7]. Although these changes are only short-lived and of few consequence in healthy individuals, they may have detrimental effects on the coronary or cerebral circulation of high-risk patients [8].

There are many studies done in different countries which compare the effect of intravenous fentanyl with lidocaine as part of anesthetics adjuvant on attenuation of hemodynamic pressor responses to laryngoscopic intubation but there are conflicting results [9] [10] [11] [12]. Hence, the primary outcome of this study is to compare the post-intubation hemodynamic parameters (heart rate and blood pressure) between fentanyl and lidocaine group for attenuation of pressor responses during intubation. The secondary outcomes are to compare the baseline hemodynamic parameters with post-intubation hemodynamic parameters in each group.

\section{Method}

Ethical clearance was obtained from Addis Ababa University ethical clearance committee before the start of the study. This study was conducted in Tikur Anbessa specialized Hospital (TASH) which is one of the largest teaching and referral hospital in Addis Ababa, capital of Ethiopia.

Study design: Institution based comparative observational cohort study was conducted from Jan 1, 2018 to March 30, 2018.

Source population: All adult patients who were scheduled for elective surgeries under general anesthesia with Laryngoscopic intubation at Tikur Anbessa Specialized Hospital during the study period.

Study population: Patient who underwent elective surgeries under general anesthesia with Laryngoscopic intubation at Tikur Anbessa Specialized Hospital during the study period and fulfills inclusion criteria.

Inclusion criteria: ASA I \& II patients and Age (18 - 65) years.

Exclusion criteria: Allergy to study drug, Patients receiving cardio vascular drugs, Patients with difficult intubation, more than one attempt to intubation, Obstetric patient and Neurosurgical patient were excluded.

Sample size and sampling technique: Sample size was calculated using the following formula (Comparison of two means) for continuous outcomes based on a previous study done in India [9] which showed a DBP mean and standard deviation of $86 \pm 4.04 \mathrm{mmHg}$ and $84 \pm 3.27 \mathrm{mmHg}$ among the Lidocaine and Fentanyl groups respectively after intubation. With level of significance being $5 \%, Z=$ confidence level at $95 \%$ (standard value of 1.96 ) and power of $80 \%$.

$$
n=\frac{\left(S_{1}^{2}+S_{2}^{2}\right)}{\left(\mu_{1}-\mu_{2}\right)^{2}}(Z \alpha / 2+Z \beta)^{2}
$$

where 
$Z \alpha / 2=1.96$ for a $p=0.05$ (95\% confidence interval).

$Z \beta=0.84$ for $20 \%$ beta error.

$S=$ standard deviation.

$\mu=\mathrm{SBP}$ mean.

$$
n=\frac{(4.04)^{2}+(3.27)^{2}}{(86-84)^{2}}(1.96+0.84)^{2}
$$

$n=53.015956 \approx 54$ patients in each group.

Five percent of additional sample was included by assuming loss to follow up and a total of 57 samples for each group were calculated.

During the study period, 216 patients were estimated to undergo surgery under general anesthesia with laryngoscopic intubation in the hospital. With systematic random sampling, every $2^{\text {nd }}$ patients who were scheduled for surgery under general anesthesia, fulfill inclusion criteria and volunteer were recruited to take part in the study. Since randomized control trial (RCT) was not yet allowed in our university, the patients were not randomized for anesthetic management. Rather by starting at random, every selected participant was placed to either group based on the responsible anesthetist's pre-operative hemodynamic pressor responses management plan (whether they received Fentanyl or lidocaine). Anesthetic management including pre-operative and intra-operative usage of anesthetics and anesthetics adjuvant were at the discretion of the personnel anesthetist assigned to each case. We the investigators did not involve in the per-operative management of patients. Those patients who received intravenous fentanyl 2 micrograms per kilogram three minutes before intubation were considered as group F. The Lidocaine group was defined, in this study, as those patients who receive intravenous $2 \%$ lidocaine 1.5 milligrams per kilogram three minute before intubation. This continues until the desired sample in each group was achieved. Participant's involvement in the study was on voluntary bases, participants who were not willing to participate in the study \& those who wish to quit their participation at any stage was informed to do so without any restriction.

In the pre-operative period patients were transferred to surgical waiting area and then to Operation Room (OR). In the OR patients were observed by two blinded data collectors (anesthetist). The hemodynamic parameters of the patients were recorded at three minutes before intubation (baseline), first $\left(1^{\text {st }}\right)$ minute after intubation, third $\left(3^{\text {rd }}\right)$ minute after intubation and fifth $\left(5^{\text {th }}\right)$ minute after intubation from anesthesia monitoring. Socio-demographic and other factors are recorded from anesthesia recording sheets and patient's medical record. Data were checked for completeness, accuracy and clarity by the investigators.

\section{a) Data processing and analysis:}

Data were coded, edited and then entered and cleaned using Epi Info version 7.2 and exported and analyzed using Statistical package for Social Sciences (SPSS) software version 20.0. Shapiro Wilk test was used to test for distributions of data while homogeneity of variance was assessed using Levene's test for 
equality of variance. Numeric data were described in terms of mean \pm SD. Comparisons of numerical variables between and within study groups were done using unpaired student $\mathrm{t}$-test (independent $\mathrm{t}$-test) and dependent $\mathrm{t}$-test respectively. Frequency and percentage were used to describe categorical variables and statistical differences between groups were tested using Chi-square or Fisher's exact test, as appropriate. Significance was determined at $\mathrm{P}$ value $<0.05$.

Operational Definition: the following definitions were used for this study.

Hemodynamic parameters: heart rate, systolic blood pressure and diastolic blood pressure which were measured and recorded at three minutes before intubation (baseline), $1^{\text {st }}$ minute after intubation, $3^{\text {rd }}$ minute after intubation and $5^{\text {th }}$ minute after intubation.

Fentanyl $2 \mathrm{mcg} / \mathrm{kg}$ : The usual dose most commonly used for attenuation pressor responses during induction of anesthesia.

Lidocaine (2\%) $1.5 \mathrm{mg} / \mathrm{kg}$ : Intravenous preparation plain lidocaine used for attenuation of per-operative arrhythmias.

Laryngoscopic intubation (LI): Insertion of flexible tube or airway device in the trachea by using laryngoscopy.

\section{Results}

\subsection{Demographic and Per-Operative Characteristics}

A total of one hundred and fourteen respondents participated in this study. Out of 114 respondents, 57 were group "F" and 57 were group "L", all were included in the study as they were complete and showed the consistency of responses. Among the study participants who were included in this study, 73 (64\%) were female and 41 (36\%) were male. There was no significant difference between two groups in mean age, mean difference $(\mathrm{M})=0.667,95 \% \mathrm{CI}[-3.97,5.3], \mathrm{t}(112)=$ $0.285, \mathrm{p}=0.776$, the minimum and maximum ages were 18 and 65 years respectively in group "F" and 18 and 62 years in group "L". The demographic status and clinical characteristics of data were comparable between groups with $\mathrm{p}$ value greater than 0.05 (Table 1).

\subsection{Comparisons of Heart Rate between Groups}

There was no statistical significant difference between the two groups regarding the baseline (before intubation) heart rate (Table 2). After intubation heart rate was statistical significantly lower in fentanyl group compared to lidocaine at first and third minute after intubation ( $\mathrm{p}<0.006$ and $\mathrm{p}<0.037$ respectively). There was no statistically significant difference in heart rate among the group at fifth minute after intubation $(\mathrm{p}>0.05)$ (Table 2).

\subsection{Comparisons of SBP between Groups}

Independent sample t-test showed that there was no statistical significant difference at baseline SBP between the groups ( $p>0.05$ ). SBP was statistical significantly lower in fentanyl group compared to lidocaine group at first minute after 
Table 1. Demographic and clinical characteristics of the study participants who underwent elective surgery under general anesthesia with laryngoscopic intubation at TASH, from January 1-March 30, 2018.

\begin{tabular}{|c|c|c|c|c|}
\hline \multicolumn{2}{|c|}{ Characteristics } & Fentanyl $(\mathrm{n}=57)$ & Lidocaine $(\mathrm{n}=57)$ & $\mathrm{P}$-value \\
\hline \multirow[b]{2}{*}{ Sex } & Female (n, \%) & $35(61.4)$ & $38(66.7)$ & \multirow[b]{2}{*}{0.558} \\
\hline & Male $(n, \%)$ & $22(38.6)$ & $19(33.3)$ & \\
\hline \multicolumn{2}{|c|}{ Age (years) $($ mean $\pm S D)$} & $38.5 \pm 12.53$ & $39.19 \pm 12.45$ & 0.776 \\
\hline \multicolumn{2}{|c|}{ Weight $(\mathrm{kg})($ mean $\pm \mathrm{SD})$} & $68.9 \pm 8.3$ & $67.9 \pm 8.5$ & 0.53 \\
\hline \multirow[b]{2}{*}{ ASA } & $\mathrm{I}(\mathrm{n}, \%)$ & $37(64.9)$ & $37(64.9)$ & \multirow[b]{2}{*}{0.32} \\
\hline & II $(\mathrm{n}, \%)$ & $20(35.1)$ & $20(35.1)$ & \\
\hline \multirow{2}{*}{ Mallapatti classification } & $\mathrm{I}(\mathrm{n}, \%)$ & $42(73.3)$ & $42(73.3)$ & \multirow{2}{*}{0.33} \\
\hline & II $(\mathrm{n}, \%)$ & $15(26.3)$ & $15(26.3)$ & \\
\hline \multirow{2}{*}{ Induction agent } & Propofol (n, \%) & $30(52.6)$ & $32(56.1)$ & \multirow{2}{*}{0.50} \\
\hline & Thiopental (n, \%) & $27(47.4)$ & 25 (43.9) & \\
\hline \multirow{5}{*}{ Surgical procedure } & GI surgery (n, \%) & $23(40.4)$ & $15(26.3)$ & \multirow{5}{*}{0.372} \\
\hline & Gynecology (n, \%) & $17(29.8)$ & $16(28.1)$ & \\
\hline & ENT $(n, \%)$ & $4(7)$ & $7(12.3)$ & \\
\hline & Urology (n, \%) & $5(8.8)$ & $10(17.5)$ & \\
\hline & Other (n, \%) & $8(14)$ & $9(15.8)$ & \\
\hline
\end{tabular}

$(\mathrm{n}=$ number of participant, $(\%)=$ percentage, ASA = American society of anesthesiology physical status, $\mathrm{SD}=$ standard deviation.).

Table 2. Baseline and after intubation heart rate between fentanyl and lidocaine groups in the study participants who underwent elective surgery under GA at TASH, from January 1-March 30, 2018.

\begin{tabular}{cccc}
\hline Heart rate & Fentanyl (Mean \pm SD) & Lidocaine (Mean \pm SD) & P-value \\
\hline At Baseline & $92.26 \pm 18.3 \mathrm{bpm}$ & $95.68 \pm 16 \mathrm{bpm}$ & 0.288 \\
At $1^{\text {st }}$ Min. & $98.91 \pm 15.6 \mathrm{bpm}$ & $107 \pm 15.45 \mathrm{bpm}$ & $<0.006^{\star}$ \\
At $3^{\text {rd }}$ Min. & $94.7 \pm 15 \mathrm{bpm}$ & $100.6 \pm 15 \mathrm{bpm}$ & $<0.037^{\star}$ \\
At $5^{\text {th }}$ Min. & $91.25 \pm 15.3 \mathrm{bpm}$ & $93.84 \pm 15 \mathrm{bpm}$ & 0.362 \\
\hline
\end{tabular}

$\mathrm{b} / \mathrm{n}=$ between, $\mathrm{SD}=$ standard deviation, $\mathrm{F}=$ fentanyl, $\mathrm{L}=$ lidocaine, At $1^{\text {st }} \mathrm{min}=$ at $1^{\text {st }}$ minute after intubation, At $3^{\text {rd }} \min =$ At $3^{\text {rd }}$ minute after intubation, at $5^{\text {th }} \min =$ at $5^{\text {th }}$ minute after intubation, ${ }^{*}=$ Statistically Significant).

intubation $(\mathrm{p}<0.016)$. There was no statistically significant difference in SBP among the group at third and fifth minute after intubation $(\mathrm{p}>0.05)$ (Table 3$)$.

\subsection{Comparisons of DBP between Groups}

There was no significant difference between the two groups regarding before induction (baseline) Diastolic blood pressure (DBP) of the study participants $(\mathrm{p}>0.05)$. Independent sample t-test showed that DBP was statistical significantly lower in fentanyl group compared to lidocaine group at first minute after 
Table 3. SBP between fentanyl and lidocaine groups in study participants who underwent elective surgery under GA at TASH, from January 1-March 30, 2018.

\begin{tabular}{cccc}
\hline SBP & Fentanyl (Mean \pm SD) & Lidocaine $($ Mean \pm SD) & P-value \\
\hline At Baseline & $132.19 \pm 15 \mathrm{mmHg}$ & $132.8 \pm 16 \mathrm{mmHg}$ & 0.824 \\
At $1^{\text {st }}$ min. & $141.9 \pm 18.9 \mathrm{mmHg}$ & $150 \pm 18.098 \mathrm{mmHg}$ & $0.016^{*}$ \\
At $3^{\text {rd }}$ min. & $127.7 \pm 15.2 \mathrm{mmHg}$ & $132.65 \pm 16 \mathrm{mmHg}$ & 0.094 \\
At $5^{\text {th }}$ min. & $120.25 \pm 16.8 \mathrm{mmHg}$ & $123.19 \pm 14.1 \mathrm{mmHg}$ & 0.313 \\
\hline
\end{tabular}

$(\mathrm{b} / \mathrm{n}=$ between, $\mathrm{SD}=$ standard deviation, $\mathrm{SBP}=$ systolic blood pressure, $\mathrm{mmHg}=$ millimeter of mercury, At $1^{\text {st }} \min =$ at $1^{\text {st }}$ minute after intubation, At $3^{\text {rd }} \min =$ at $3^{\text {rd }}$ minute after intubation, At $5^{\text {th }}$ min $=$ at $5^{\text {th }}$ minute after intubation, ${ }^{*}=$ statistical significant).

intubation $(\mathrm{p}<0.047)$. There was no statistically significant difference in DBP among the group at third and fifth minute after intubation $(p>0.05)$ (Table 4).

\subsection{Comparisons of Heart Rate within the Group}

The paired sample t-test showed that there was initial rise in heart rate from baseline at first minute after intubation and third minute after intubation both in lidocaine and fentanyl group $(\mathrm{p}<0.01)$. At fifth minute after intubation, heart rate return to baseline and slightly below baseline both in fentanyl and lidocaine group $(\mathrm{p}>0.05)$ (Table 5).

\subsection{Comparisons of SBP within the Group}

The paired sample t-test showed that SBP was statistically significantly raised from baseline at first minute after intubation both in fentanyl and lidocaine group $(\mathrm{p}<0.01)$. At third minute after intubation SBP return to baseline both in fentanyl and lidocaine group ( $p>0.05$ ). But at fifth minute after intubation SBP was significantly decreased from baseline in both groups $(\mathrm{p}<0.001)($ Table 6$)$.

\subsection{Comparisons of DBP within the Group}

DBP was significantly increased from baseline at first minute after intubation both in fentanyl and lidocaine group $(\mathrm{p}<0.01)$. At third minute after intubation DBP return to baseline both in fentanyl and lidocaine group $(p>0.05)$. But at fifth minute after intubation DBP was significantly decreased from baseline in both groups $(\mathrm{p}<0.001)$ (Table 7).

\section{Discussion}

Stress responses to laryngoscopy and endotracheal intubation in form of tachycardia, hypertension, ventricular tachycardia and arrhythmias may be associated with significant moribund outcome. This hemodynamic change is due to reflex sympathetic discharge caused by epipharyngeal and laryngopharyngeal stimulation [2]. Thus, a variety of anesthetics agent combinations and anesthetics adjuvants have undergone many prospective studies and clinical trials in relation to study attenuation of pressor responses to laryngoscopic intubation [13]. 
Table 4. DBP between fentanyl and lidocaine group in study participants who underwent elective surgery under GA at TASH, from January 1-March 30, 2018.

\begin{tabular}{cccc}
\hline DBP & Fentanyl (Mean \pm SD) & Lidocaine (Mean \pm SD) & P-value \\
\hline At Baseline & $84.07 \pm 10.9 \mathrm{mmHg}$ & $84.91 \pm 14 \mathrm{mmHg}$ & 0.716 \\
At $1^{\text {st }}$ min. & $91.7 \pm 13 \mathrm{mmHg}$ & $95.06 \pm 14 \mathrm{mmHg}$ & $0.049^{*}$ \\
At $3^{\text {rd }}$ min. & $82.11 \pm 12.6 \mathrm{mmHg}$ & $85.63 \pm 15 \mathrm{mmHg}$ & 0.177 \\
At $5^{\text {th }}$ min. & $77.02 \pm 12 \mathrm{mmHg}$ & $80.7 \pm 13.4 \mathrm{mmHg}$ & 0.125
\end{tabular}

$\left(\mathrm{SD}=\right.$ standard deviation, $\mathrm{DBP}=$ diastolic blood pressure, At $1^{\text {st }} \min =$ at $1^{\text {st }}$ minute after intubation, At $3^{\text {rd }} \min =$ at $3^{\text {rd }}$ minute after intubation, At $5^{\text {th }}$ min $=$ at $5^{\text {th }}$ minute after intubation, ${ }^{*}=$ statistically significant).

Table 5. Mean heart rate within fentanyl and lidocaine group in study participants who underwent elective surgery under GA at TASH, from January 1-March 30, 2018.

\begin{tabular}{|c|c|c|c|c|c|c|}
\hline Heart rate & $\begin{array}{c}\text { Fentanyl } \\
(\text { Mean } \pm \text { SD })\end{array}$ & $\begin{array}{l}\text { Magnitude of raise } \\
\text { from baseline in } \\
\text { F-group }\end{array}$ & $\begin{array}{l}\text { P-value for mean } \\
\text { difference with in } \\
\text { F-group }\end{array}$ & $\begin{array}{c}\text { Lidocaine } \\
(\text { Mean } \pm \text { SD) }\end{array}$ & $\begin{array}{l}\text { Magnitude of raise } \\
\text { from baseline in } \\
\text { L-group }\end{array}$ & $\begin{array}{l}\text { P-value for mean } \\
\text { difference within } \\
\text { L-group }\end{array}$ \\
\hline At Baseline & $92.26 \pm 18.3 \mathrm{bpm}$ & & - & $95.68 \pm 16 \mathrm{bpm}$ & & - \\
\hline At $1^{\mathrm{st}} \mathrm{min}$. & $98.91 \pm 15.6 \mathrm{bpm}$ & $7.2 \% \uparrow$ & $0.001^{*}$ & $107 \pm 15.45 \mathrm{bpm}$ & $12 \% \uparrow$ & $0.001^{*}$ \\
\hline At $3^{\text {rd }} \mathrm{min}$ & $94.7 \pm 15 \mathrm{bpm}$ & $1.11 \% \uparrow$ & 0.141 & $100.6 \pm 15 \mathrm{bpm}$ & $5.14 \% \uparrow$ & $0.001^{*}$ \\
\hline At $5^{\text {th }} \mathrm{min}$. & $91.25 \pm 15.3 \mathrm{bpm}$ & $1.1 \% \downarrow$ & 0.565 & $93.84 \pm 15 \mathrm{bpm}$ & $1.9 \% \downarrow$ & 0.230 \\
\hline
\end{tabular}

$\left(\mathrm{b} / \mathrm{n}=\right.$ between, $\mathrm{SD}=$ standard deviation, $\mathrm{F}=$ fentanyl, $\mathrm{L}=$ lidocaine, At $1^{\text {st }}$ min $=$ at $1^{\text {st }}$ minute after intubation, At $3^{\text {rd }}$ min $=$ At $3^{\text {rd }}$ minute after intubation, at $5^{\text {th }} \min =$ at $5^{\text {th }}$ minute after intubation, $\uparrow=$ increase, $\downarrow=$ decrease, ${ }^{*}=$ statistically significant, bpm $=$ beat per minute).

Table 6. Mean SBP within fentanyl and lidocaine group in study participants who underwent elective surgery under GA at TASH, from January 1-March 30, 2018.

\begin{tabular}{|c|c|c|c|c|c|c|}
\hline SBP & $\begin{array}{c}\text { Fentanyl } \\
(\text { Mean } \pm \mathrm{SD})\end{array}$ & $\begin{array}{l}\text { Magnitude of } \\
\text { raise from base- } \\
\text { line In F-group }\end{array}$ & $\begin{array}{l}\text { P-value for } \\
\text { mean difference } \\
\text { within F-group }\end{array}$ & $\begin{array}{c}\text { Lidocaine } \\
(\text { Mean } \pm \mathrm{SD})\end{array}$ & $\begin{array}{l}\text { Magnitude of raise } \\
\text { from baseline } \\
\text { In L-group }\end{array}$ & $\begin{array}{l}\text { P-value for mean dif- } \\
\text { ference within L-group }\end{array}$ \\
\hline Baseline & $132.19 \pm 15 \mathrm{mmHg}$ & & - & $132.8 \pm 16 \mathrm{mmHg}$ & & - \\
\hline At $1^{\text {st }} \min$. & $141.9 \pm 18.9 \mathrm{mmHg}$ & $7.35 \% \uparrow$ & $0.001^{\star}$ & $150 \pm 18.098 \mathrm{mmHg}$ & $13 \% \uparrow$ & $0.001^{\star}$ \\
\hline At $3^{\text {rd }} \min$. & $127.7 \pm 15.2 \mathrm{mmHg}$ & $3.4 \% \downarrow$ & 0.05 & $132.65 \pm 16 \mathrm{mmHg}$ & $0.1 \% \downarrow$ & 0.896 \\
\hline At $5^{\text {th }} \mathrm{min}$. & $120.25 \pm 16.8 \mathrm{mmHg}$ & $6 \% \downarrow$ & $0.001^{*}$ & $123.19 \pm 14.1 \mathrm{mmHg}$ & $7 \% \downarrow$ & $0.001^{\star}$ \\
\hline
\end{tabular}

$\left(\mathrm{b} / \mathrm{n}=\right.$ between, $\mathrm{SD}=$ standard deviation, $\mathrm{SBP}=$ systolic blood pressure, $\mathrm{mmHg}=$ millimeter of mercury, At $1^{\text {st }}$ min $=$ at $1^{\text {st }}$ minute after intubation, At $3^{\text {rd }}$ $\min =$ at $3^{\text {rd }}$ minute after intubation, At $5^{\text {th }} \min =$ at $5^{\text {th }}$ minute after intubation, $\uparrow=$ increase, $\downarrow=$ decrease, ${ }^{*}=$ statistically significant).

Table 7. Mean DBP within fentanyl and lidocaine group in study participants who underwent elective surgery under GA at TASH, from January 1-March 30, 2018.

\begin{tabular}{|c|c|c|c|c|c|c|}
\hline DBP & $\begin{array}{c}\text { Fentanyl } \\
(\text { Mean } \pm \text { SD })\end{array}$ & $\begin{array}{l}\text { Magnitude of raise } \\
\text { from baseline in } \\
\text { F-group }\end{array}$ & $\begin{array}{c}\text { P-value for mean } \\
\text { Difference within F } \\
\text { group }\end{array}$ & $\begin{array}{c}\text { Lidocaine } \\
(\text { Mean } \pm \text { SD })\end{array}$ & $\begin{array}{l}\text { Magnitude of raise } \\
\text { from baseline in } \\
\text { L-group }\end{array}$ & $\begin{array}{c}\text { P-value for mean } \\
\text { difference within } \\
\text { L-group }\end{array}$ \\
\hline Baseline & $84.07 \pm 10.9 \mathrm{mmHg}$ & & - & $84.91 \pm 14 \mathrm{mmHg}$ & & - \\
\hline At $1 \mathrm{~min}$. & $91.7 \pm 13 \mathrm{mmHg}$ & $9.07 \% \uparrow$ & 0.001 & $95.06 \pm 14 \mathrm{mmHg}$ & $12 \% \uparrow$ & 0.001 \\
\hline At $3 \mathrm{~min}$. & $82.11 \pm 12.6 \mathrm{mmHg}$ & $2.3 \% \downarrow$ & 0.232 & $85.63 \pm 15 \mathrm{mmHg}$ & $1 \% \uparrow$ & 0.896 \\
\hline At $5 \mathrm{~min}$. & $77.02 \pm 12 \mathrm{mmHg}$ & $8 \% \downarrow$ & 0.05 & $80.7 \pm 13.4 \mathrm{mmHg}$ & $5 \% \downarrow$ & 0.19 \\
\hline
\end{tabular}

$\left(\mathrm{SD}=\right.$ standard deviation, $\mathrm{DBP}=$ diastolic blood pressure, At $1^{\text {st }} \mathrm{min}=$ at $1^{\text {st }}$ minute after intubation, At $3^{\text {rd }}$ min $=$ at $3^{\text {rd }}$ minute after intubation, At $5^{\text {th }}$ min $=$ at $5^{\text {th }}$ minute after intubation, $\uparrow=$ increase, $\downarrow=$ decrease, ${ }^{*}=$ statistically significant). 
According to our study the heart rate in bpm with mean \pm SD was significantly lower in fentanyl group (98.91 bpm $\pm 15.6 \mathrm{bpm}$ ) when compared to lidocaine group $(107 \mathrm{bpm} \pm 15.45 \mathrm{bpm})$ at first minute after intubation $(\mathrm{p}<0.006)$. Heart rate was also lower in fentanyl group compared to lidocaine group at third minute after intubation $(\mathrm{P}<0.037)$. SBP with mean \pm SD was also lower in fentanyl group (141.9 $\mathrm{mmHg} \pm 18.9 \mathrm{mmHg}$ ) compared to lidocaine group (150 $\mathrm{mmHg} \pm 18.098 \mathrm{mmHg})$ at first minute after intubation $(\mathrm{p}=0.016)$. The possible explanation for this may be Fentanyl brings hemodynamic stability during peri-operative period by its action on cardiovascular and autonomic regulatory areas. It decreases sympathetic tone and increases parasympathetic tone.

A randomized control trial study by Jyothsna Yadav et al. (2017) shows similar finding to our study, comparing fentanyl and lidocaine on attenuation of hemodynamic responses to laryngoscopic intubation observed that heart rate in lidocaine group after intubation was $89 \mathrm{bpm} \pm 2.33 \mathrm{bpm}$, which was significantly higher compared to fentanyl group $82.40 \mathrm{bpm} \pm 1.66 \mathrm{bpm}(\mathrm{p}=0.000)$. The average increase in heart rate above baseline was significantly lower in fentanyl group compared to lidocaine group $(\mathrm{p}=0.000)$. The magnitude of increase in SBP above baseline in lidocaine group and fentanyl group were $(9.9 \%)$ and (7.07\%) $\mathrm{mmHg}$ respectively which was statistically significant $(\mathrm{p}=0.000)$ [9]. Also, a study was done in Korea (2007) showed that the heart rate was significantly lower in fentanyl group compared to lidocaine group at first, second and third minute after intubation $(\mathrm{p}>0.05)$ [14]. Same results were reported in another study [15].

Our study was in contrary with study done in India (2016) a prospective, randomized, double-blind study on 120 patients that compare, the effects of lidocaine, fentanyl, and Esmolol on hemodynamics and bispectral index when used before laryngoscopy and intubation to prevent stress responses stated that there were no significant difference between fentanyl $(109.80 \pm 11.78 \mathrm{bpm})$ and lidocaine $(103.63 \pm 13.813 \mathrm{bpm})$ in producing hemodynamic stability at first minute after intubation when compared to each other $(\mathrm{p}=0.305)$ [10].

The result of this study showed the there were no significant difference in SBP and DBP at third minute after intubation between fentanyl and lidocaine group ( $\mathrm{p}=0.413$ and 0.194 respectively). In contrary to this study, the randomized control trial study was done in Turkey (2012) stated that there were significant difference in SBP and DBP at Third minute after intubation between fentanyl and lidocaine group $(\mathrm{p}<0.05)$ [11].

Our study found that heart rate was slightly returned to baseline at third minute and fifth minute after intubation in fentanyl and lidocaine group respectively. This study was in line with prospective studies done in Iran (2017) on 96 patients stated that lidocaine effectively prevents heart rate fluctuations following the endotracheal intubation at $3^{\text {rd }}$ and $5^{\text {th }}$ minute after intubation [16].

\section{Limitation of the Study}

Making blind for data collectors was not possible due to operation theatre 
setup.

$\checkmark$ Lack of control group.

\section{Conclusion}

The findings of our study demonstrate that fentanyl $2 \mu \mathrm{g} / \mathrm{kg} \mathrm{IV}$, administered three minutes before intubation, was better in attenuating hemodynamic responses to laryngoscopic intubation compared with $2 \%$ lidocaine $1.5 \mathrm{mg} / \mathrm{kg}$ IV in patients undergoing elective surgeries under general anesthesia with laryngoscopic intubation. But clinically, lidocaine provides a consistent and reliable attenuation of press or responses at fifth minute after intubation as comparable to fentanyl.

\section{Funding}

This work was funded by Addis Ababa University.

\section{Disclosure}

The authors have no conflicts of interest to declare.

\section{Availability of Data and Material}

The data used in this study was collected by trained data collectors and authors are willing to share the data upon request from peer researchers.

\section{Acknowledgements}

We would like to thank Addis Ababa University College of Medicine and Health Science for funding this research. Our gratitude goes to supervisors, data collectors and study respondents. Finally, we would like to thank all those, who in one way or another have contribute to this work.

\section{Conflicts of Interest}

The authors declare no conflicts of interest regarding the publication of this paper.

\section{References}

[1] Kovac, L. (1996) Controlling the Hemodynamic Response to Laryngoscopy and Endotracheal Intubation. Journal of Clinical Anesthesia, 8, 63-79. https://doi.org/10.1016/0952-8180(95)00147-6

[2] Shribman, A.J., Smith, G. and Achola, K.J. (1987) Cardiovascular and Catecholamine Responses to Laryngoscopy with and without Tracheal Intubation. British Journal of Anaesthesia, 59, 295-299. https://doi.org/10.1093/bja/59.3.295

[3] Joffe, A.M. and Deem, S.A. (2012) Physiologic and Pathophysiologic Responses to Intubation. In: Benumof and Hagberg's Airway Management, 3rd Edition, Elsevier Inc., \Amsterdam, Netherlands. https://doi.org/10.1016/B978-1-4377-2764-7.00007-5

[4] Fa, K. and Ullah, H. (2013) Pharmacological Agents for Preventing Morbidity As- 
sociated with the Haemodynamic Response to Tracheal Intubation. Cochrane Database of Systematic Reviews, No. 7, CD004087.

[5] Mi, W.D., Sakai, T., Takahashi, S. and Matsuki, A. (1998) Haemodynamic and Electroencephalograph Responses to Intubation during Induction with Propofol or Propofol/Fentanyl. Canadian Journal of Anaesthesia, 45, 19-22.

https://doi.org/10.1007/BF03011986

https://www.ncbi.nlm.nih.gov/pubmed/9466021

[6] Dunn, L.K. and Durieux, M.E. (2017) Perioperative Use of Intravenous Lidocaine. Anesthesiology, 126, 729-737. https://doi.org/10.1097/ALN.0000000000001527

[7] Rehman, A.U., Abbas, N. and Siddiqui, A.S. (2013) Haemodynamic Response to Conventional Tracheal Intubation and Classic Laryngeal Mask Airway in Patients Coming for Elective Procedures : A Single Blinded Randomized Controlled. Medical Channel, 19, 56-59.

[8] Forbes, A.M. and Dally, F.G. (1970) Acute Hypertension during Induction of Anaesthesia and Endotracheal Intubation in Normotensive Man. British Journal of Anaesthesia, 42, 618-624. https://doi.org/10.1093/bja/42.7.618

[9] Jyothsna, Y.C. Vuppala, A. and Kotha, R. (2017) Attenuation of Cardiovascular Response during Direct Laryngoscopy and Intubation: A Comparative Study between Fentanyl, Lignocaine and Placebo during General Anaesthesia. International Journal of Advanced Research, 5, 918-924. https://doi.org/10.21474/IJAR01/4494

[10] Routray, S.S., Mohapatra, R., Mishra, D. and Swain, A. (2016) Effects of Lidocaine, Fentanyl and Esmolol on Haemodynamics and Bispectral Index When Used before Laryngoscopy and Intubation to Prevent Stress Response in Patients with Etomidate Induction. Scholars Journal of Applied Medical Sciences, 4, 3514-3519.

[11] Gurulingappa, A., Awati, M.N. and Adarsh, S. (2012) Attenuation of Cardiovascular Responses to Direct Laryngoscopy and Intubation-A Comparative Study between IV Bolus Fentanyl, Lignocaine and Placebo (NS). Journal of Clinical and Diagnostic Research, 6, 1749-1752.

[12] Siddiqui, M.A.K. and Kiran, N. (2015) Analytical Study of Effects of Intravenous Lignocaine on Pressor Response during Laryngoscopy and Intubation. International Journal of Biomedical Research, 6, 104-107. https://doi.org/10.7439/ijbr.v6i2.1670

[13] Jit, S., Bajwa, S., Kaur, J., Singh, A., Kulshrestha, A., Gupta, S., et al. (2012) Attenuation of Pressor Response and Dose Sparing of Opioids and Anaesthetics with Pre-Operative Dexmedetomidine. Clinical Investigation, 56, 123-128. https://doi.org/10.4103/0019-5049.96303

[14] Shin, H.Y., Kim, J.W., Kim, A.R., Jang, Y.H., Kim, J.M. and Bae, J.I. (2007) The Effects of Lidocaine, Fentanyl, Nicardipine, and Esmolol on Hemodynamic and Bispectral Index Responses during Induction with Thiopental Sodium. Korean Journal of Anesthesiology, 53, S7-S13. https://doi.org/10.4097/kjae.2007.53.3.S7

[15] Mohite, A., Patil, D., Paranjpe, J., Kumar, V., Dorkar, J. and Jadhav, K. (2015) Comparison of Two Different Doses of Fentanyl in Attenuation of Haemodynamic Responses during Laryngoscopy \& Endotracheal. International Journal of Health Sciences \& Research, 5, 58-65.

[16] Hashemian, A.M., Zamani, H., Doloo, M., Saadatfar, M., Moallem, R., Moradifar, M., et al. (2017) Effects of Intravenous Administration of Fentanyl and Lidocaine on Hemodynamic Responses Following Endotracheal Intubation. The American Journal of Emergency Medicine, 36, 197-201. 


\section{Abbreviations}

ASA-The American Society of Anesthesiologists physical state classification GA-General Anesthesia

DBP_Diastolic Arterial Pressure

CI-Confidence Interval

SPSS-Statistical Package for Social Science

ETT-Endotracheal Tube

HR-Heart Rate

IV-Intravenous

SBP-Systolic Arterial Pressure

TASH_Tikur Anbessa Specialized Hospital 